\title{
Neuroprotective Effects of Korean Red Pine (Pinus densiflora) Bark Extract and Its Phenolics
}

\author{
Ji-Won Kim ${ }^{1,2}$, Sungbin $\operatorname{Im}^{1,2}$, Ha-Ram Jeong ${ }^{1,2}$, Young Sung Jung ${ }^{1,2}$, Inil Lee ${ }^{1,2}$, Kwan Joong Kim ${ }^{1,2}$, \\ Seung Kook Park ${ }^{1}$, and Dae-Ok Kim ${ }^{1,2 *}$ \\ ${ }^{1}$ Department of Food Science and Biotechnology, Kyung Hee University, Yongin 17104, Republic of Korea \\ ${ }^{2}$ Skin Biotechnology Center, Kyung Hee University, Suwon 16229, Republic of Korea
}

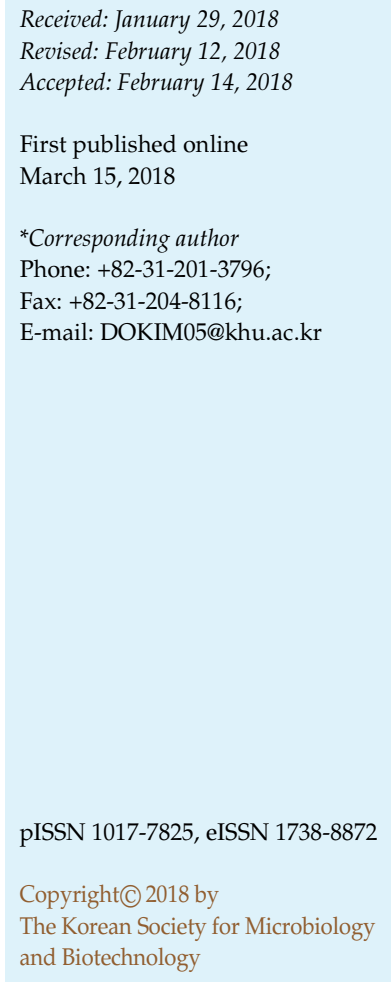

Korean red pine (Pinus densiflora) is one of the major Pinus species in Korea. Red pine bark is removed prior to the chipping process in the wood industry and discarded as waste. However, red pine bark contains a considerable amount of naturally occurring phenolics, including flavonoids, and therefore may have a variety of biological effects. In this study, we investigated if Korean red pine bark extract (KRPBE) could protect neuronal PC-12 cells from oxidative stress and inhibit cholinesterase activity. Analysis of reversed-phase high-performance liquid chromatography results revealed four phenolics in KRPBE: vanillin, protocatechuic acid, catechin, and taxifolin. The total phenolic and flavonoid contents of KRPBE were $397.9 \mathrm{mg}$ gallic acid equivalents/g dry weight (DW) and $248.7 \mathrm{mg}$ catechin equivalents/g DW, respectively. The antioxidant capacities of KRPBE measured using ABTS, DPPH, and ORAC assays were 697.3, 521.8, and 2,627.7 $\mathrm{mg}$ vitamin C equivalents/g DW, respectively. KRPBE and its identified phenolics protected against $\mathrm{H}_{2} \mathrm{O}_{2}$-induced oxidative cell death in a dosedependent manner. Acetylcholinesterase and butyrylcholinesterase, which degrade the neurotransmitter acetylcholine to terminate neurotransmission in synaptic clefts, were inhibited by treatment with KRPBE and its identified phenolics. Taken together, these results suggest that KRPBE and its constituent antioxidative phenolics are potent neuroprotective agents that can maintain cell viability under oxidative stress and inhibit cholinesterase activity.

Keywords: Acetylcholinesterase, antioxidant capacity, butyrylcholinesterase, oxidative stress, PineXol ${ }^{\circledR}$, taxifolin

\section{Introduction}

Alzheimer's disease (AD) is an age-dependent, chronic, neurodegenerative disorder characterized by symptoms of progressive decline in activities of daily living, cognitive impairment, and memory deficits [1]. Oxidative stress generated by reactive oxygen species (ROS), including hydrogen peroxide and superoxide, is associated with the apoptosis of neuronal cells in neurodegenerative disorders [2]. When not sufficiently scavenged, oxidative stress may cause lipid peroxidation of membranes and lead to excessive cell death, a characteristic of many neurological disorders. Antioxidants can reduce oxidative stress in the body and may protect neuronal cells against oxidative stress. In addition, AD could potentially be treated by maintaining the level of acetylcholine, a neurotransmitter, by inhibiting the activity of cholinesterases, including acetylcholinesterase (AChE) and butyrylcholinesterase (BChE), with reversible inhibitors. AChE exists mainly in neurons, whereas $\mathrm{BChE}$ is associated primarily with glial cells and white matter [3]. The principal role of AChE is termination of nerve transmission at cholinergic synapses by rapid hydrolysis of acetylcholine. AChE and BChE inhibitors improve endogenous levels of acetylcholine in the brain of $\mathrm{AD}$ patients, thereby prolonging cholinergic neurotransmission. However, synthetic drugs such as 
donepezil, tacrine, and rivastigmine that are used to treat the cognitive functional disorders and memory loss associated with $\mathrm{AD}$ have side effects and can result in digestive disorders [4]. Hence, identifying antioxidants and cholinesterase inhibitors from natural resources may yield non-toxic treatments that can halt AD progression.

Pine bark is removed prior to the chipping process in the lumber industry [5]. Although pine bark complicates wood processing, it has high contents of phenolics and lignins [5, 6]. Lignins are cross-linked polymers with phenolic structures. Large amounts of pine bark are generated as waste, although pine bark is used as a boiler fuel. Pine bark has been reported to contain procyanidins, flavonoids such as taxifolin and catechin, and phenolic acids such as ferulic, caffeic, cinnamic, and $p$-hydroxybenzoic acids [6, 7]. Procyanidin, which is a condensed tannin, is a polymer made up of subunits of catechin and epicatechin with various chain lengths and is one of the major polymeric phenolics in pine bark [8]. Procyanidins, flavonoids, and phenolic acids have been reported to have potent antioxidant capacity, which is dependent on the number of hydroxyl groups in their structures [9, 10]. Catechins (flavan-3-ols) exert potent neuroprotective effects partly due to their iron-chelating and radical-scavenging properties [11]. Phenolics, including catechin and procyanidin B2, have been reported to have neuroprotective effects by inhibiting AChE and BChE $[12,13]$.

Natural phenolics show a wide variety of healthpromoting effects, including antioxidative, anti-cholinesterase, anticancer, and anti-inflammatory activities [13]. Phenolics are used in the food industry in a variety of applications, including as food colorants and antioxidants [14]. Phenolics are also used in the fields of cosmetics and pharmaceutics to protect against oxidative stress [15]. French maritime pine (Pinus pinaster) bark extract $\left(\right.$ Pycnogenol $\left.^{\circledR}\right)$ is a wellknown commercial product utilized as a health-promoting supplement and as a phytochemical disease treatment worldwide [16]. Pycnogenol ${ }^{\circledast}$ has been reported to have photoprotective, antimicrobial, free radical scavenging, and neuroprotective properties against oxidative stress [15, 16]. Korean red pine (Pinus densiflora Sieb. et Zucc.) has been reported to have higher amounts of total phenolics and flavonoids as well as antioxidant capacity in bark than other pine species [5]. The total phenolic and flavonoid contents of Korean red pine bark extract (KRPBE; PineXol ${ }^{\circledR}$ ) were reported previously [17]. PineXol ${ }^{\circledR}$ significantly reduced lipid accumulation in 3T3-L1 cells, suggesting that it has anti-adipogenic effects [17].

The biological activity of Pycnogenol ${ }^{\circledR}$, including its neuroprotective ability, has been studied extensively. However, little is known about the antioxidative and neuroprotective effects of KRPBE. In the present study, we evaluated the total phenolic content, total flavonoid content, antioxidant capacity, and cell protective effects of KRPBE on neuronal PC-12 cells exposed to oxidative stress. We also used a reversed-phase high-performance liquid chromatography (HPLC) system to determine the phenolic constituents of KRPBE, and its anti-cholinesterase activity was examined using $\mathrm{AChE}$ and $\mathrm{BChE}$ inhibition assays.

\section{Materials and Methods}

\section{Samples and Reagents}

KRPBE (PineXol ${ }^{\circledR}$ ) was obtained from Nutrapharm Ltd. (Korea). Folin-Ciocalteu's phenol reagent, 2,2'-azino-bis(3-ethylbenzothiazoline6-sulfonic acid) diammonium salt (ABTS), 2,2'-azobis(2-amidinopropane) dihydrochloride (AAPH), 2,2-diphenyl-1-picrylhydrazyl (DPPH), gallic acid, catechin, vanillin, protocatechuic acid, taxifolin, ascorbic acid, hydrogen peroxide $\left(\mathrm{H}_{2} \mathrm{O}_{2}\right)$, dimethyl sulfoxide (DMSO), 2',7'-dichlorofluorescin diacetate (DCFH-DA), 3-(4,5dimethylthiazol-2-yl)-2,5-diphenyltetrazolium bromide (MTT), AChE, BChE, acetylcholine iodide (ATCI), butyrylthiocholine chloride (BTCC), 9-amino-1,2,3,4-tetrahydroacridine hydrochloride hydrate (tacrine), 5,5'-dithiobis(2-nitrobenzoic acid) (DTNB), and phosphate-buffered saline (PBS) were purchased from Sigma Aldrich Co., LLC (USA). Roswell Park Memorial Institute (RPMI)1640 medium, fetal bovine serum (FBS), penicillin/streptomycin, Hank's balanced salt solution (HBSS), and Dulbecco's phosphatebuffered saline (DPBS) were purchased from Welgene Inc. (Korea). All other reagents used were of analytical or HPLC grade.

\section{Determination of Total Phenolic Content}

The total phenolic content of KRPBE was measured using a colorimetric method with Folin-Ciocalteu's phenol reagent [18, 19]. Two hundred microliters of appropriately diluted KRPBE or gallic acid standard was mixed with $2.6 \mathrm{ml}$ of deionized water. At $0 \mathrm{~min}, 200 \mu \mathrm{l}$ of Folin-Ciocalteu's phenol reagent was added to the mixture. At $6 \mathrm{~min}, 2 \mathrm{ml}$ of $7 \%(\mathrm{w} / \mathrm{v}) \mathrm{Na}_{2} \mathrm{CO}_{3}$ solution was added. At $90 \mathrm{~min}$, the absorbance was measured at $750 \mathrm{~nm}$ using a spectrophotometer (Spectronic 200; Thermo Fisher Scientific Inc., USA). The total phenolic content was expressed as mg gallic acid equivalents (GAE)/g dry weight (DW) of KRPBE.

\section{Determination of Total Flavonoid Content}

The total flavonoid content of KRPBE was measured using the method of Liu et al. [20]. Briefly, $500 \mu \mathrm{l}$ of diluted KRPBE or catechin standard was mixed with $3.2 \mathrm{ml}$ of deionized water, and then $150 \mu \mathrm{l}$ of $5 \%(\mathrm{w} / \mathrm{v}) \mathrm{NaNO}_{2}$ was added. At $5 \mathrm{~min}, 150 \mu \mathrm{l}$ of $10 \%(\mathrm{w} / \mathrm{v}) \mathrm{AlCl}_{3}$ was added. At $6 \mathrm{~min}, 1 \mathrm{ml}$ of $1 \mathrm{M} \mathrm{NaOH}$ was added. Absorbance was measured immediately at $510 \mathrm{~nm}$ using a spectrophotometer (Spectronic 200). The total flavonoid content 
was expressed as mg catechin equivalents (CE)/g DW of KRPBE.

Determination of the Antioxidant Capacity of KRPBE using ABTS and DPPH Radical Assays and the Oxygen Radical Absorbance Capacity (ORAC) Assay

The antioxidant capacity of KRPBE was also assessed using ABTS radicals [21] and expressed as $\mathrm{mg}$ vitamin $\mathrm{C}$ equivalents (VCE)/g DW of KRPBE. The ABTS radical solution was adjusted to an absorbance of $0.650 \pm 0.020$ at $734 \mathrm{~nm}$. The reaction between ABTS radicals and the appropriately diluted samples was allowed to proceed at $37^{\circ} \mathrm{C}$ for $10 \mathrm{~min}$, and then the decrease in absorbance of the resulting solution was measured at $734 \mathrm{~nm}$ using a spectrophotometer (Spectronic 200).

The antioxidant capacity of KRPBE was also measured using DPPH radicals [21] and expressed as mg VCE/g DW of KRPBE. The absorbance of DPPH radicals in $80 \%(\mathrm{v} / \mathrm{v})$ aqueous methanol was set to $0.650 \pm 0.020$ at $517 \mathrm{~nm}$. DPPH radicals and appropriately diluted samples or vitamin $\mathrm{C}$ standard were reacted at $23^{\circ} \mathrm{C}$ for 30 $\mathrm{min}$. The decrease in absorbance of the resulting solution was monitored at $517 \mathrm{~nm}$ using a spectrophotometer (Spectronic 200).

The ORAC assay was further performed to determine the antioxidant capacity of KRPBE [22]. Appropriately diluted KRPBE $(25 \mu \mathrm{l})$ and $150 \mu \mathrm{l}$ of $81.6 \mathrm{nM}$ fluorescein solution were added to a 96-well plate and incubated at $37^{\circ} \mathrm{C}$ for $10 \mathrm{~min}$ with $3 \mathrm{~min}$ of shaking. We added $25 \mu \mathrm{l}$ of $153 \mathrm{mM} \mathrm{AAPH}$ solution and then detected the fluorescence every minute for $90 \mathrm{~min}$ using a microplate reader (Infinite M200; Tecan Austria GmbH, Austria) with $485 \mathrm{~nm}$ excitation and $520 \mathrm{~nm}$ emission wavelengths. The antioxidant capacity measured by ORAC assay was expressed as $\mathrm{mg} \mathrm{VCE} / \mathrm{g}$ DW of KRPBE.

\section{Quantification of Phenolics Using HPLC}

KRPBE was quantitatively analyzed using a reversed-phase HPLC system (Agilent 1200; Agilent Technologies, USA) equipped with a diode-array detector, degasser, autosampler, and a reversedphase column (Agilent Zorbax Eclipse XDB-C18, $250 \times 4.6 \mathrm{~mm}$, $5 \mu \mathrm{m})$. The injection volume was $20 \mu \mathrm{l}$, and the flow rate was $1.0 \mathrm{ml} / \mathrm{min}$. Mobile phase A consisted of $0.1 \%(\mathrm{v} / \mathrm{v})$ formic acid in deionized water, and mobile phase $\mathrm{B}$ was acetonitrile. The gradient elution profile was as follows: $95 \% \mathrm{~A} / 5 \% \mathrm{~B}$ at $0 \mathrm{~min}, 5 \%$ $\mathrm{A} / 95 \% \mathrm{~B}$ at $45 \mathrm{~min}, 95 \% \mathrm{~A} / 5 \% \mathrm{~B}$ at $46 \mathrm{~min}$, and $95 \% \mathrm{~A} / 5 \% \mathrm{~B}$ at $50 \mathrm{~min}$. The wavelengths for detection were set at $280 \mathrm{~nm}$ for protocatechuic acid and catechin and at $320 \mathrm{~nm}$ for vanillin and taxifolin. Phenolics were identified by comparison of UV-Vis spectra, retention times, and spiked inputs with commercial standards. Phenolics were quantified using calibration curves that relate different concentrations of authentic standards to the areas of their corresponding peaks.

\section{Cell Culture}

Neuronal PC-12 cells (ATCC, USA) were used to assess the effects of KRPBE on cell viability and intracellular oxidative stress. PC-12 cells were cultured in RPMI 1640 medium containing
$10 \%$ heat-inactivated FBS, 100 units $/ \mathrm{ml}$ penicillin, and $100 \mu \mathrm{g} / \mathrm{ml}$ of streptomycin in a humidified incubator (BB 15; Thermo Fisher Scientific Inc., USA) with $5 \% \mathrm{CO}_{2}$ at $37^{\circ} \mathrm{C}$.

\section{Determination of Cell Viability}

To determine the non-toxic maximal concentration of KRPBE, its cytotoxicity was assessed using an MTT reduction assay [23]. MTT is metabolized to insoluble purple formazan by mitochondrial dehydrogenases, which are active only in living cells. PC-12 cells were seeded at a density of $2 \times 10^{4}$ cells/well in a 96-well plate in RPMI 1640 medium containing FBS, for $12 \mathrm{~h}$. After removing the medium, cells were treated with serum-free medium containing various concentrations of KRPBE at various non-toxic concentrations or a positive standard ( $200 \mu \mathrm{M}$ of vitamin C). Following a 6 -h incubation, the medium was removed from each well, and $200 \mu \mathrm{M}$ of $\mathrm{H}_{2} \mathrm{O}_{2}$ was added to induce oxidative stress for $1 \mathrm{~h}$. Then, MTT reagent was added, the plate was incubated for $3 \mathrm{~h}$, and then $50 \mu \mathrm{l}$ of DMSO was added to dissolve the purple formazan formed by reduction of MTT. The absorbance was measured using a microplate reader (Infinite M200) at $570 \mathrm{~nm}$ (test wavelength) and $630 \mathrm{~nm}$ (reference wavelength). Cell viability was expressed as the percentage $(\%)$ of viable cells relative to control cells cultured without test samples.

\section{Measurement of Intracellular Oxidative Stress}

Intracellular oxidative stress was determined by fluorescent assay using DCFH-DA. DCFH-DA is deacetylated in cells, and then $2^{\prime}, 7^{\prime}$-dichlorofluorescin reacts with intracellular oxidative radicals and is converted into the fluorescent product $2^{\prime}, 7^{\prime}-$ dichlorofluorescein, which is retained within cells. PC-12 cells were seeded at a density of $2 \times 10^{4}$ cells/well in a 96-well plate in RPMI 1640 medium and incubated for $24 \mathrm{~h}$. The cells were then treated with non-toxic concentrations $(0.625-10 \mu \mathrm{g} / \mathrm{ml})$ of KRPBE or positive standard (vitamin C) for $4 \mathrm{~h}$. After removing the supernatant, $50 \mu \mathrm{M}$ DCFH-DA in HBSS was added. At $30 \mathrm{~min}$, oxidative stress was induced with $200 \mu \mathrm{M} \mathrm{H}_{2} \mathrm{O}_{2}$ for $1 \mathrm{~h}$. Fluorescence was measured using a microplate reader (Infinite M200) with excitation at $485 \mathrm{~nm}$ and emission at $530 \mathrm{~nm}$.

\section{Determination of Cholinesterase Inhibition Activity}

We determined anticholinesterase activity using $\mathrm{AChE}$ and BChE assays performed in a 96-well plate [24]. Substrates ATCI and BTCC were used for the AChE and BChE inhibitory assays, respectively. In both assays, DTNB was used as the colordeveloping reagent. For the AChE inhibition assay, $20 \mu \mathrm{l}$ of KRPBE or phenolic compound was added to $150 \mu \mathrm{l}$ of DPBS. Subsequently, $20 \mu \mathrm{l}$ of ATCI substrate $(15 \mathrm{mM})$ and $30 \mu \mathrm{l}$ of DTNB $(10 \mathrm{mM})$ were added to the mixture. After incubation for $10 \mathrm{~min}$ at $37^{\circ} \mathrm{C}, 20 \mu \mathrm{l}$ of $\mathrm{AChE}(0.4 \mathrm{U} / \mathrm{ml})$ was added. The BChE inhibition assay was performed using a similar protocol, except that instead of AChE and ATCI, we used $0.065 \mathrm{U} / \mathrm{ml} \mathrm{BChE}$ and $10 \mathrm{mM}$ BTCC. After $30 \mathrm{~min}$ at $37^{\circ} \mathrm{C}$, we measured the absorbance at $415 \mathrm{~nm}$ using a microplate reader (Infinite M200). Tacrine was used as a positive 
control. We made a tacrine standard curve relating various concentrations of tacrine to cholinesterase inhibition (\%) for quantitative evaluation of the cholinesterase inhibitory activity in KRPBE. Inhibition of $\mathrm{AChE}$ and $\mathrm{BChE}$ in response to KRPBE was expressed as $\mathrm{nM}$ of tacrine equivalents (TE). Measurement of the $\mathrm{AChE}$ and BChE inhibitory activities of KRPBE was performed in triplicate.

\section{Statistical Analysis}

Data are expressed as the mean \pm standard deviation of three replicate determinations. One-way analysis of variance was applied to determine the significance of differences among means. Statistical analyses were conducted using Duncan's multiple range test using SAS software (version 9.3, SAS Institute Inc., USA), with significance set at $p<0.05$.

\section{Results and Discussion}

\section{Total Phenolic and Flavonoid Contents}

The total phenolic content of KRPBE as a crude water extract powder was $397.9 \mathrm{mg} \mathrm{GAE} / \mathrm{g}$ DW (Table 1). In a previous study, bark samples from five different maritime pine (P. pinaster) trees grown in France were reported to have a total phenolic content of 37.21-96.81 mg GAE/g dry bark, due to the differences in age of the trees [25]. Pinus cembra L. bark collected in Romania was reported to have a total phenolic content of $299.3 \mathrm{mg}$ GAE/g freeze-dried extract [26]. Pinus densiflora extracted with hot water was reported to have a total phenolic content of $411 \mathrm{mg} \mathrm{CE} / \mathrm{g}$ [5]. Inconsistent with our finding in this study, the total phenolic content of PineXol ${ }^{\circledR}$ was previously reported to be $717.4 \mathrm{mg} \mathrm{GAE} / \mathrm{g}$ [17]; this discrepancy may be due to the manufacturing process, harvest season, growing location, and/or species. It was previously reported that P. densiflora bark extract had a higher total phenolic content than $P$. thunbergii and $P$. pinaster bark extracts [27].

The KRPBE used in this study had a total flavonoid content of $248.7 \mathrm{mg} \mathrm{CE} / \mathrm{g}$ DW (Table 1). Consistent with this result, a P. cembra L. bark sample collected in Romania was previously reported to have a total flavonoid content of $299.3 \mathrm{mg} \mathrm{CE} / \mathrm{g}$ freeze-dried extract [26]. The total flavonoid content of PineXol ${ }^{\circledR}$ has been reported to be approximately $54.4 \mathrm{mg}$ rutin equivalent/g [17].

\section{Antioxidant Capacity}

The antioxidant capacity of KRPBE was measured using ABTS, DPPH, and ORAC assays. Results are shown in Table 1. In the ABTS, DPPH, and ORAC assays, KRPBE had an antioxidant capacity of $697.3,521.8$, and $2,627.7 \mathrm{mg}$ $\mathrm{VCE} / \mathrm{g}$ DW, respectively. The bark extract of $P$. morrisonicola Hay. was reported to have the ability to scavenge superoxide radical anions and to inhibit lipid peroxidation, due in part to its antioxidant constituents [28]. It was previously reported that PineXol ${ }^{\circledR}$ had an antioxidant capacity of 693.97 $\mu \mathrm{M}$ Trolox equivalents/g in the ORAC assay [17]. In the DPPH assay, $P$. densiflora was reported to have the most potent antioxidant capacity among bark from 11 species of pine, and the main contributor to its antioxidant capacity was procyanidins [5]. KRPBE has been reported to have higher ABTS and DPPH radical scavenging activities than Pycnogenol ${ }^{\circledR}$ [29]. In contrast to our ABTS and DPPH assay results, PineXol ${ }^{\circledR}$ was reported to have higher antioxidant capacity than vitamin C [17].

\section{Quantification of Phenolics in KRPBE Using a Reversed- Phase HPLC System}

The concentrations of four phenolic compounds (catechin, protocatechuic acid, taxifolin, and vanillin) in KRPBE are presented in Table 2. The concentrations of the four phenolic compounds decreased as follows: catechin $(24.5 \mathrm{mg} / \mathrm{g})>$ taxifolin $(7.7 \mathrm{mg} / \mathrm{g})>$ protocatechuic acid $(6.1 \mathrm{mg} / \mathrm{g})>$ vanillin $(2.3 \mathrm{mg} / \mathrm{g})$. A previous study reported that KRPBE contained catechin, taxifolin, and oligomers of catechin and epicatechin [29]. Extract of the raw pine bark of P. maritima collected in France has been reported to contain a variety of phenolics, including catechin, protocatechuic acid, taxifolin, and vanillin [30]. Consistent with our findings in this

Table 1. Total phenolic and flavonoid contents and antioxidant capacity of Korean red pine bark extract (KRPBE).

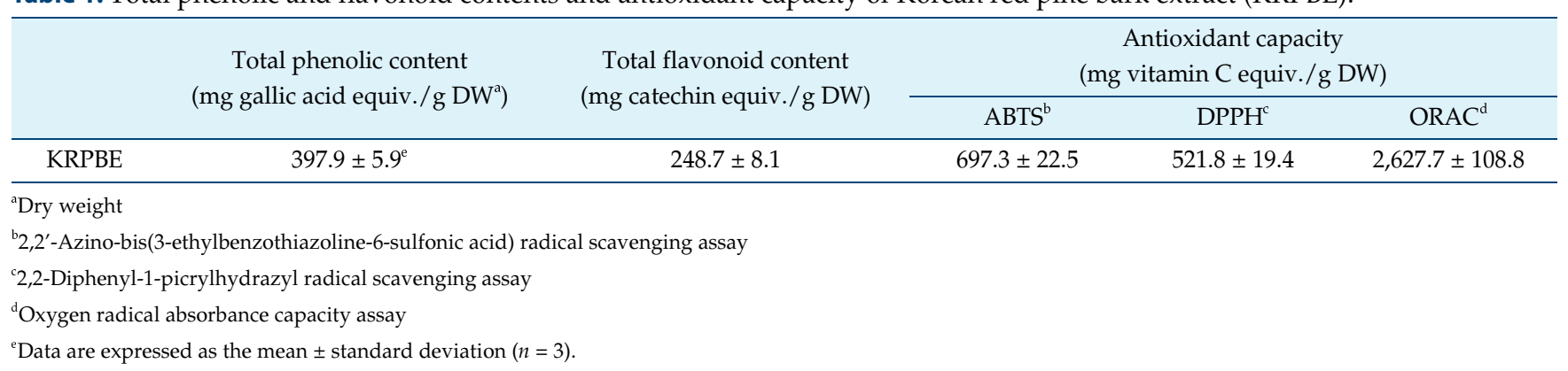


Table 2. Concentrations of phenolics in Korean red pine bark extract.

\begin{tabular}{cc}
\hline Phenolics & Concentration $(\mathrm{mg} / \mathrm{g})$ \\
\hline Catechin & $24.5 \pm 4.0$ \\
Protocatechuic acid & $6.1 \pm 0.1$ \\
Taxifolin & $7.7 \pm 0.5$ \\
Vanillin & $2.3 \pm 0.2$ \\
\hline
\end{tabular}

study, taxifolin, catechin, and protocatechuic acid were previously reported to be the major monomeric phenolics in $P$. radiata bark [6].

\section{Protective Effects of KRPBE and Its Identified Phenolics on the Viability of PC-12 Cells}

The cytotoxicity of KRPBE was examined to determine at what concentrations it was not toxic. Cell viability of $90 \%$ or above compared with the control $(100 \%)$ was considered to be non-cytotoxic. KRPBE had no cytotoxicity against neuron-like PC-12 cells up to $10 \mu \mathrm{g} / \mathrm{ml}$ (Fig. 1A). PC-12 cells are derived from a pheochromocytoma of the rat adrenal medulla. Oxidative stress $\left(200 \mu \mathrm{M}\right.$ of $\left.\mathrm{H}_{2} \mathrm{O}_{2}\right)$ decreased the viability of PC-12 cells up to approximately $60.5 \%$ (Fig. 1B). Pretreatment of PC-12 cells with KRPBE and vitamin $C$ increased their viability in response to exposure to oxidative stress. Pretreatment with KRPBE at $10 \mu \mathrm{g} / \mathrm{ml}$ followed by oxidative stress treatment resulted in a cell viability of $77.7 \%$ compared with the control $(100 \%)$, which was similar to the cell viability $(78.1 \%)$ of the positive control, $200 \mu \mathrm{M}$ vitamin $\mathrm{C}$ (Fig. 1B).

We measured the viability of neuronal PC-12 cells in the presence of vanillin, protocatechuic acid, catechin, and taxifolin (Fig. 2). These four phenolics had no cytotoxicity against PC-12 cells up to $100 \mu \mathrm{g} / \mathrm{ml}$ (data not shown). The viability of oxidatively stressed PC-12 cells was not significantly increased by pretreatment with vanillin at any concentration compared with the stress control (Fig. 2). PC-12 cells pretreated with vanillin, protocatechuic acid, catechin, and taxifolin at $100 \mu \mathrm{g} / \mathrm{ml}$ had viabilities of approximately $45 \%, 57 \%, 52 \%$, and $87 \%$, respectively (Fig. 2). Protocatechuic acid and taxifolin at a concentration of $100 \mu \mathrm{g} / \mathrm{ml}$ protected PC-12 cells significantly more against oxidative stress than did the stress control (40.3\%).

Oxidative stress can damage cellular materials such as lipids, proteins, and DNA, leading to cellular malfunction and ultimately cell death. Antioxidants may protect cells, including neurons, against oxidative stress. Pine bark has been reported to have a neuroprotective effect, partly due
A

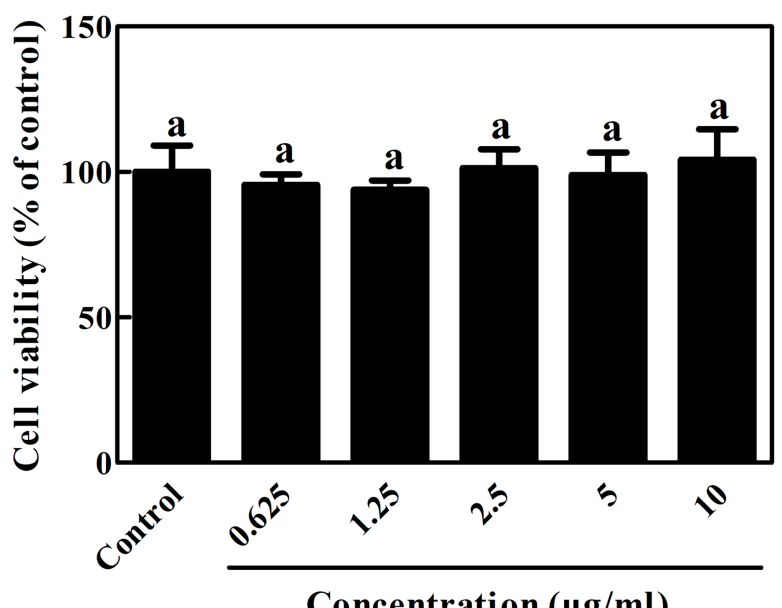

Concentration $(\mu \mathrm{g} / \mathrm{ml})$

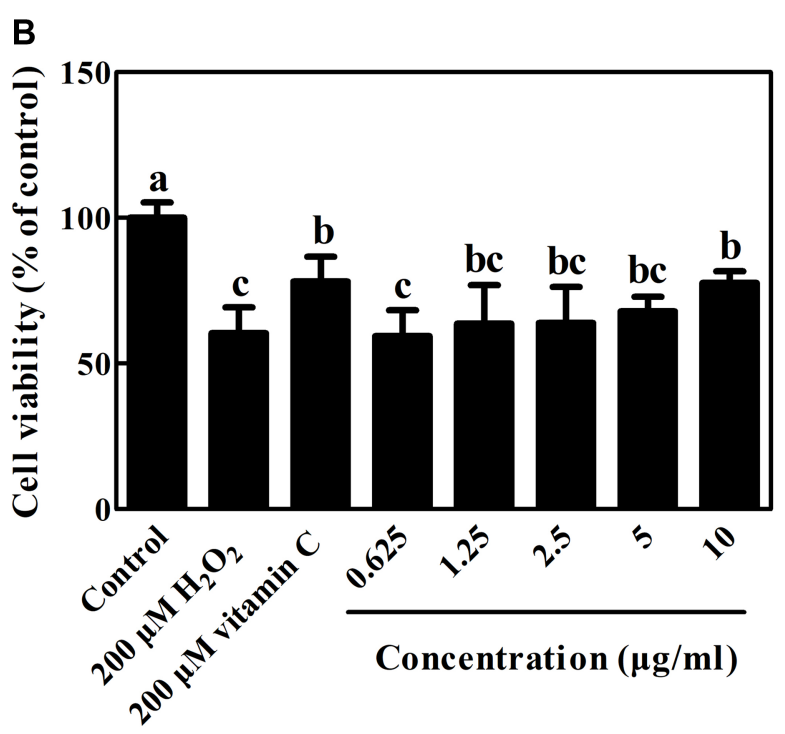

Fig. 1. (A) Cytotoxic effects of Korean red pine bark extract on neuronal PC-12 cells and (B) its protective effects against $\mathrm{H}_{2} \mathrm{O}_{2}$-induced oxidative stress as measured using the MTT assay.

Data are displayed as the mean \pm standard deviation (bars) of three replicates. Different letters on the bars indicate significant differences according to Duncan's multiple range test $(p<0.05)$.

to its antioxidant content [31]. Taxifolin has been reported to protect retinal pigment epithelial cells against $\mathrm{H}_{2} \mathrm{O}_{2}$ induced oxidative stress, partly due to the decrease of ROS production and inhibition of apoptosis [32]. Pinus radiata bark extract rich in procyanidins was demonstrated to significantly reduce protein oxidation in humans after 12 weeks of consumption [33]. Phenolics (catechin, taxifolin, vanillin, and protocatechuic acid) found in KRPBE have been reported to have antioxidant capacity [10, 34]. 


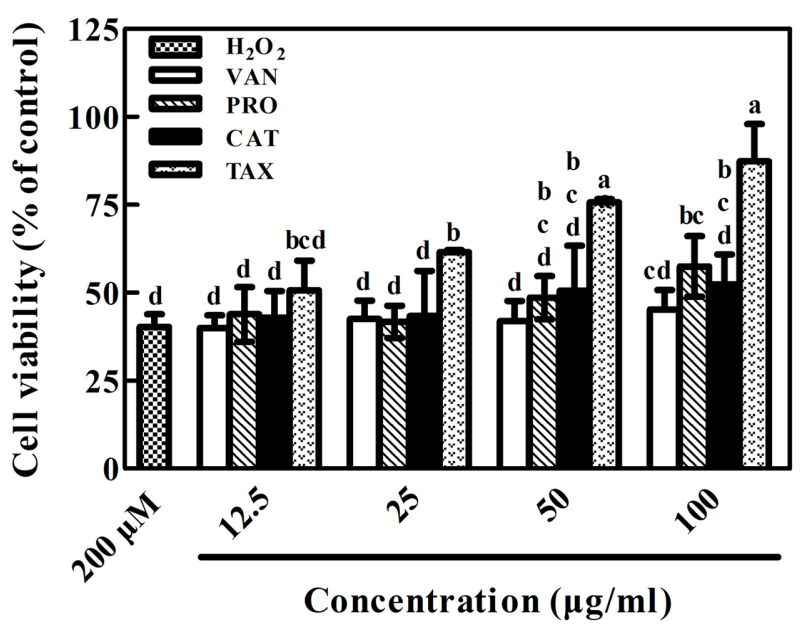

Fig. 2. Protective effects of vanillin (VAN), protocatechuic acid (PRO), catechin (CAT), and taxifolin (TAX), identified in Korean red pine bark extract, in neuronal PC-12 cells exposed to $\mathrm{H}_{2} \mathrm{O}_{2}$-induced oxidative stress, based on MTT assay results. Data are displayed as the mean \pm standard deviation (bars) of three replicates. Different letters on the bars indicate significant differences according to Duncan's multiple range test $(p<0.05)$.

Therefore, the increased viability of PC-12 cells pretreated with KRPBE in response to oxidative stress is likely due to the antioxidant activity of its phenolic constituents.

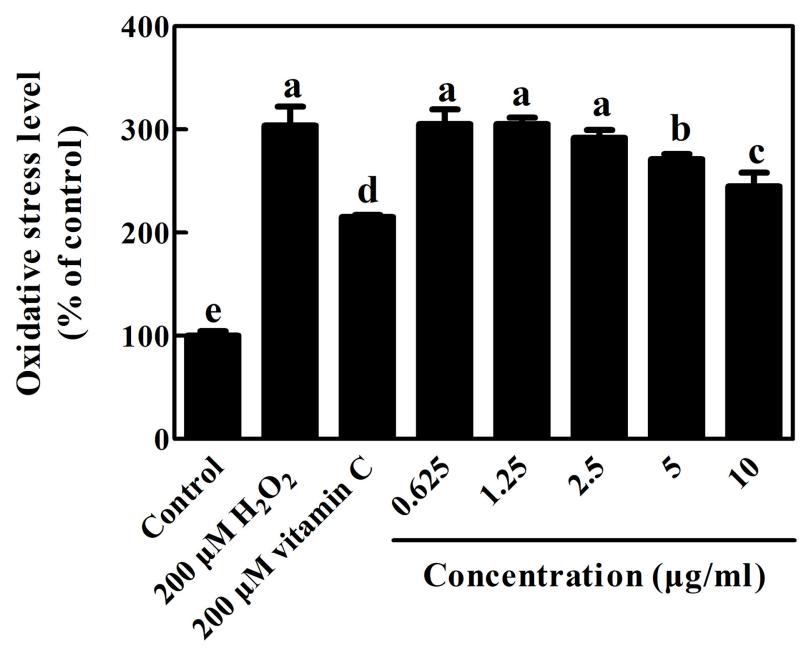

Fig. 3. Ability of Korean red pine bark extract to protect against intracellular oxidative stress in PC-12 cells exposed to $\mathrm{H}_{2} \mathrm{O}_{2}$-induced oxidative stress, as measured using the DCFHDA assay.

Data are displayed as the mean \pm standard deviation (bars) of three replicates. Different letters on the bars indicate significant differences according to Duncan's multiple range test $(p<0.05)$.
Effects of KRPBE and Its Identified Phenolics on Intracellular Oxidative Stress in PC-12 Cells

Hydrogen peroxide can penetrate cell membranes via free diffusion through the lipid bilayer of membranes and function as intracellular ROS. The DCFH-DA assay was used to evaluate oxidative stress inside neuronal PC-12 cells. Hydrogen peroxide $(200 \mu \mathrm{M})$ increased oxidative stress inside PC-12 cells up to $304 \%$ of the control level (100\%; Fig. 3). Vitamin C reduced oxidative stress to approximately $215 \%$ compared with that in stress control cells (Fig. 3). Pretreatment of PC-12 cells with KRPBE decreased oxidative stress in a dose-dependent manner compared with cells exposed to oxidative stress only (Fig. 3).

Pretreatment of PC-12 cells with the four identified phenolics at $100 \mu \mathrm{g} / \mathrm{ml}$ decreased oxidative stress levels as follows: taxifolin $(116 \%)>$ protocatechuic acid $(212 \%)>$ catechin $(234 \%)>$ vanillin $(279 \%)$ (Fig. 4). Pretreatment with taxifolin at all concentrations decreased oxidative stress in PC-12 cells in a dose-dependent manner compared with the stress control (279\%; Fig. 4). Protocatechuic acid and catechin at a concentration of $100 \mu \mathrm{g} / \mathrm{ml}$ significantly reduced oxidative stress in PC-12 cells compared with the stress control.

These results suggest that phenolic antioxidants in KRPBE may decrease intracellular oxidative stress in neuronal PC-

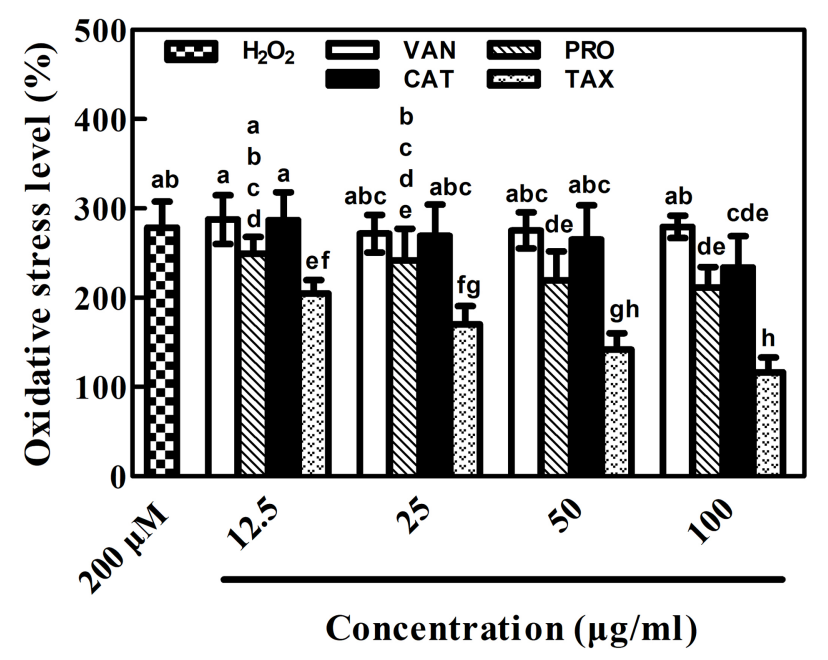

Fig. 4. Ability of vanillin (VAN), protocatechuic acid (PRO), catechin (CAT), and taxifolin (TAX), identified in Korean red pine bark extract, to protect neuronal PC-12 cells against $\mathrm{H}_{2} \mathrm{O}_{2}$-induced oxidative stress, as measured using the DCFHDA assay.

Data are displayed as the mean \pm standard deviation (bars) of three replicates. Different letters on the bars indicate significant differences according to Duncan's multiple range test $(p<0.05)$. 
12 cells against ROS like $\mathrm{H}_{2} \mathrm{O}_{2}$. It was previously reported that pine bark extract showed protective effects against oxidative stress in rats, partly due to increased antioxidant activity as well as inhibition of lipid peroxidation [35]. RBE-4 cells, which are rat cerebral capillary endothelial cells, were reported to be permeable to catechin in a timedependent manner [36]. Catechins and procyanidins can reduce oxidative membrane damage by limiting access of oxidants to the hydrophobic region of the membrane bilayer [37]. Thus, compounds in the KRPBE may protect cell membranes from $\mathrm{H}_{2} \mathrm{O}_{2}$ penetration.

\section{Effects of KRPBE and Its Identified Phenolics on AChE and BChE Activities}

Inhibition of $\mathrm{AChE}$ and $\mathrm{BChE}$ by $\mathrm{KRPBE}$ is shown in Fig. 5. KRPBE at $10 \mu \mathrm{g} / \mathrm{ml}$ and $100 \mu \mathrm{g} / \mathrm{ml}$ had TE values of approximately $68.3 \mathrm{nM}$ and $15.1 \mathrm{nM}$ for inhibition of AChE and $\mathrm{BChE}$, respectively. A higher TE means greater inhibition of enzyme activity; therefore, AChE was inhibited by KRPBE to a greater extent than BChE (Fig. 5). KRPBE inhibited the $\mathrm{AChE}$ and $\mathrm{BChE}$ activities in a dose-dependent manner. Tacrine, the positive control, had an $\mathrm{IC}_{50}$ for $\mathrm{AChE}$ and $\mathrm{BChE}$ of $1,530 \mathrm{nM}$ and $181 \mathrm{nM}$, respectively (data not shown).

$\mathrm{AChE}$ and $\mathrm{BChE}$ are detected among neurofibrillary tangles and neuritic plaques in the brain, and the neuropathology of $\mathrm{AD}$ might result from a high ratio of $\mathrm{BChE}-$ to AChE-positive glia [38, 39]. Cholinesterase inhibitors prolong neurotransmission in cholinergic synapses by increasing the brain acetylcholine level through relatively slower metabolism of released neurotransmitters such as acetylcholine, thereby enhancing neurotransmission at cholinergic synapses [40]. A BChE inhibitor has been reported to increase the level of acetylcholine and enhance cognitive function in rats [41]. Finding inhibitors for AChE and $\mathrm{BChE}$ to treat $\mathrm{AD}$ is therefore of great interest. Phenolics are known to inhibit AChE and BChE [19]. Therefore, we investigated if the phenolics found in KRPBE had AChE- and BChE-inhibitory effects.

We assessed the ability of vanillin, protocatechuic acid, catechin, and taxifolin to inhibit $\mathrm{AChE}$ and $\mathrm{BChE}$. Protocatechuic acid did not inhibit either cholinesterase (data not shown). At $1,000 \mu \mathrm{g} / \mathrm{ml}$, the AChE-inhibiting activities decreased as follows: taxifolin $(103.6 \mu \mathrm{M}$ TE) $>$ catechin $(86.4 \mu \mathrm{M} \mathrm{TE})>$ vanillin $(56.0 \mu \mathrm{M} \mathrm{TE})$; whereas the BChE-inhibiting activities decreased as follows: taxifolin $(16.4 \mu \mathrm{M}$ TE $)>$ vanillin $(8.8 \mu \mathrm{M}$ TE $)>$ catechin $(7.0 \mu \mathrm{M}$ TE $)$ (Fig. 6). Vanillin, catechin, and taxifolin inhibited AChE and $\mathrm{BChE}$ in a dose-dependent manner. Taxifolin inhibited both AChE and BChE to the greatest extent (Fig. 6).
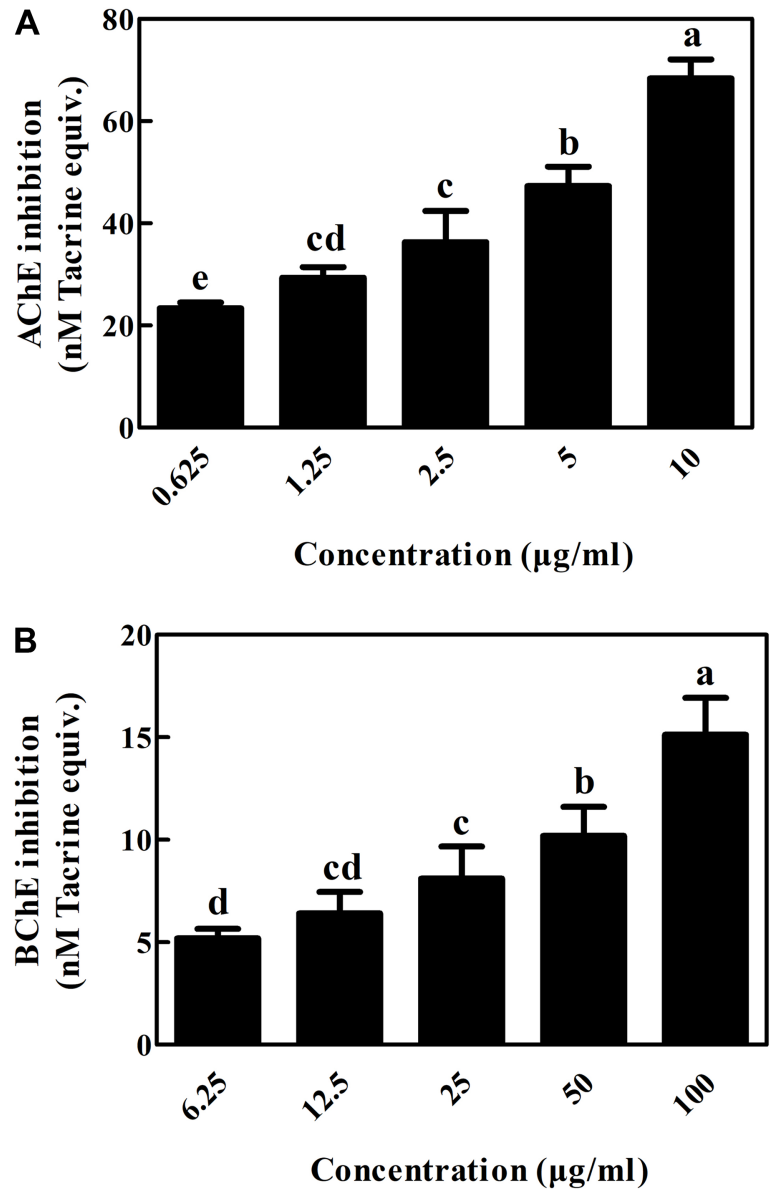

Fig. 5. Inhibitory effects of Korean red pine bark extract on acetylcholinesterase (AChE; A) and butyrylcholinesterase (BChE; B) activities.

Data are displayed as the mean \pm standard deviation (bars) of three replicates. Different letters on the bars indicate significant differences according to Duncan's multiple range test $(p<0.05)$.

Catechin has been reported to bind easily to AChE and $\mathrm{BChE}$ and then inhibit their activity, resulting in prolonged neurotransmission [38]. Flavonoids, including catechin and quercetin, can traverse RBE-4 cells, suggesting that a wide range of flavonoids and their metabolites can be delivered to nerve cells across the blood-brain barrier to inhibit AChE and BChE [36]. KRPBE, which contains vanillin, catechin, and taxifolin, could therefore be a source of therapeutic agents for $\mathrm{AD}$.

In conclusion, the KRPBE examined in this study had a high phenolic content and antioxidant capacity. Four phenolics (catechin, protocatechuic acid, taxifolin, and vanillin) were identified using a reversed-phase HPLC system. KRPBE and its identified phenolics protected neuronal PC-12 cells against oxidative stress and inhibited 

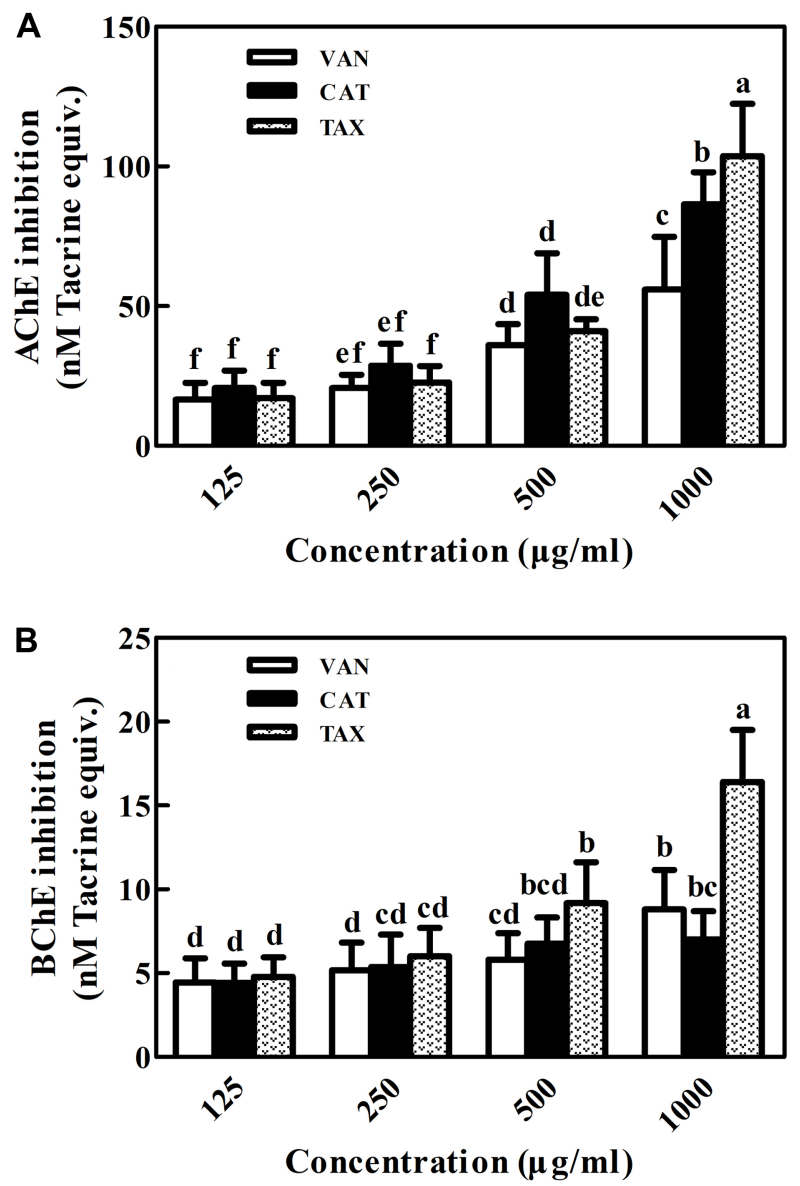

Fig. 6. Inhibitory effects of vanillin (VAN), catechin (CAT) and taxifolin (TAX), identified in Korean red pine bark extract, on acetylcholinesterase (AChE; A) and butyrylcholinesterase (BChE; B) activities.

Data are displayed as the mean \pm standard deviation (bars) of three replicates. Different letters on the bars indicate significant differences according to Duncan's multiple range test $(p<0.05)$.

$\mathrm{AChE}$ and $\mathrm{BChE}$ activities, indicating that they can prolong termination of neurotransmission. KRPBE might therefore be a good natural source of antioxidative phenolics and can potentially be used as a functional material in food and pharmaceutical applications to reduce oxidative stress and inhibit the cholinesterases. Further studies of the neuroprotective effects and bioavailability of KRPBE and its individual phenolics in in-vivo models of cognitive impairment are warranted.

\section{Acknowledgments}

This study was financially supported by a grant (No. 20140322) from Kyung Hee University.

\section{Conflict of Interest}

The authors have no financial conflicts of interest to declare.

\section{References}

1. Jekel K, Damian M, Wattmo C, Hausner L, Bullock R, Connelly PJ, et al. 2015. Mild cognitive impairment and deficits in instrumental activities of daily living: a systematic review. Alzheimers Res. Ther. 7: 17.

2. Méndez-Armenta M, Nava-Ruíz C, Juárez-Rebollar D, Rodríguez-Martínez E, Gómez PY. 2014. Oxidative stress associated with neuronal apoptosis in experimental models of epilepsy. Oxid. Med. Cell. Longev. 2014: 293689.

3. Darvesh S. 2016. Butyrylcholinesterase as a diagnostic and therapeutic target for Alzheime's disease. Curr. Alzheimer Res. 13: 1173-1177.

4. Mehta M, Adem A, Sabbagh M. 2012. New acetylcholinesterase inhibitors for Alzheimer's disease. Int. J. Alzheimers Dis. 2012: 728983

5. Ku CS, Jang JP, Mun SP. 2007. Exploitation of polyphenolrich pine barks for potent antioxidant activity. J. Wood Sci. 53: 524-528.

6. Ku CS, Mun SP. 2008. Antioxidant properties of monomeric, oligomeric, and polymeric fractions in hot water extract from Pinus radiata bark. Wood Sci. Technol. 42: 47-60.

7. D'Andrea G. 2010. Pycnogenol: a blend of procyanidins with multifaceted therapeutic applications? Fitoterapia 81: 724-736.

8. Jerez M, Pinelo M, Sineiro J, Núñez MJ. 2006. Influence of extraction conditions on phenolic yields from pine bark: assessment of procyanidins polymerization degree by thiolysis. Food Chem. 94: 406-414.

9. Floegel A, Kim D-O, Chung S-J, Song WO, Fernandez ML, Bruno RS, et al. 2010. Development and validation of an algorithm to establish a total antioxidant capacity database of the US diet. Int. J. Food Sci. Nutr. 61: 600-623.

10. Kim D-O, Lee CY. 2004. Comprehensive study of vitamin C equivalent antioxidant capacity (VCEAC) of various polyphenolics in scavenging a free radical and its structural relationship. Crit. Rev. Food Sci. Nutr. 44: 253-273.

11. Mandel S, Youdim MBH. 2004. Catechin polyphenols: neurodegeneration and neuroprotection in neurodegenerative diseases. Free Radic. Biol. Med. 37: 304-317.

12. Szwajgier D. 2013. Anticholinesterase activities of selected polyphenols - a short report. Pol. J. Food Nutr. Sci. 64: 59-64.

13. Panche AN, Diwan AD, Chandra SR. 2016. Flavonoids: an overview. J. Nutr. Sci. 5: e47.

14. Giusti MM, Wrolstad RE. 2003. Acylated anthocyanins from edible sources and their applications in food systems. Biochem. Eng. J. 14: 217-225. 
15. Iravani S, Zolfaghari B. 2011. Pharmaceutical and nutraceutical effects of Pinus pinaster bark extract. Res. Pharm. Sci. 6: 1-11.

16. Maimoona A, Naeem I, Saddiqe Z, Jameel K. 2011. A review on biological, nutraceutical and clinical aspects of French maritime pine bark extract. J. Ethnopharmacol. 133: 261-277.

17. Lee YJ, Han OT, Choi H-S, Lee BY, Chung H-J, Lee O-H. 2013. Antioxidant and anti-adipogenic effects of PineXol ${ }^{\circledR}$. Korean J. Food Sci. Technol. 45: 97-103.

18. Singleton VL, Rossi JA Jr. 1965. Colorimetry of total phenolics with phosphomolybdic-phosphotungstic acid reagents. Am. J. Enol. Vitic. 16: 144-158.

19. Choi J, An X, Lee BH, Lee JS, Heo HJ, Kim T, et al. 2015. Protective effects of bioactive phenolics from jujube (Ziziphus jujuba) seeds against $\mathrm{H}_{2} \mathrm{O}_{2}$-induced oxidative stress in neuronal PC-12 cells. Food Sci. Biotechnol. 24: 2219-2227.

20. Liu C-S, Nam T-G, Han M-W, Ahn S-M, Choi HS, Kim TY, et al. 2013. Protective effect of detoxified Rhus verniciflua Stokes on human keratinocytes and dermal fibroblasts against oxidative stress and identification of the bioactive phenolics. Biosci. Biotechnol. Biochem. 77: 1682-1688.

21. Kim D-O, Lee KW, Lee HJ, Lee CY. 2002. Vitamin C equivalent antioxidant capacity (VCEAC) of phenolic phytochemicals. J. Agric. Food Chem. 50: 3713-3717.

22. Lim D, Kim W, Lee M-G, Heo HJ, Chun OK, Kim D-O. 2012. Evidence for protective effects of coffees on oxidative stress-induced apoptosis through antioxidant capacity of phenolics. Food Sci. Biotechnol. 21: 1735-1744.

23. Heo H-J, Cho H-Y, Hong B, Kim H-K, Kim E-K, Kim B-G, et al. 2001. Protective effect of $4^{\prime}, 5$-dihydroxy-3',6,7-trimethoxyflavone from Artemisia asiatica against $\mathrm{A} \beta$-induced oxidative stress in PC12 cells. Amyloid 8: 194-201.

24. Hwang J-S, Cho CH, Baik M-Y, Park S-K, Heo HJ, Cho Y-S, et al. 2017. Effects of freeze-drying on antioxidant and anticholinesterase activities in various cultivars of kiwifruit (Actinidia spp.). Food Sci. Biotechnol. 26: 221-228.

25. Chupin L, Motillon C, Bouhtoury FC-E, Pizzi A, Charriera B. 2013. Characterisation of maritime pine (Pinus pinaster) bark tannins extracted under different conditions by spectroscopic methods, FTIR and HPLC. Ind. Crops Prod. 49: 897-903.

26. Apetrei CL, Tuchilus C, Aprotosoaie AC, Oprea A, Malterud KE, Miron A. 2011. Chemical, antioxidant and antimicrobial investigations of Pinus cembra L. bark and needles. Molecules 16: 7773-7788.

27. Kim SM, Kang S-W, Jeon J-S, Um B-H. 2012. A comparison of Pycnogenol ${ }^{\circledR}$ and bark extracts from Pinus thunbergii and Pinus densiflora: extractability, antioxidant activity and proanthocyanidin composition. J. Med. Plant Res. 6: 2839-2849.

28. Hsu T-Y, Sheu S-C, Liaw E-T, Wang T-C, Lin C-C. 2005. Anti-oxidant activity and effect of Pinus morrisonicola Hay. on the survival of leukemia cell line U937. Phytomedicine 12: 663-669.
29. Choi J-H, Choi M-K, Han O, Han S, Chung S-J, Shim C-K, et al. 2007. Evaluation of skin absorption of catechin from topical formulations containing Korean pine bark extract (PineXol ${ }^{\circledR}$ ). J. Korean Pharm. Sci. 37: 359-364.

30. Sarikaki V, Rallis M, Tanojo H, Panteri I, Dotsikas Y, Loukas YL, et al. 2004. In vitro percutaneous absorption of pine bark extract (Pycnogenol) in human skin. J. Toxicol. Cutaneous Ocul. Toxicol. 23: 149-158.

31. Eftekhar S, Keshavarzi Z, Hadjzadeh MAR. 2016. Neuroprotective effects of pine bark and Aloe vera on the locomotor activity in focal cerebral ischemia: possible antioxidant mechanisms. J. Biomed. Eng. Med. Devices 1: 121.

32. Xie X, Feng J, Kang Z, Zhang S, Zhang L, Zhang Y, et al. 2017. Taxifolin protects RPE cells against oxidative stressinduced apoptosis. Mol. Vis. 23: 520-528.

33. Senthilmohan ST, Zhang J, Stanley RA. 2003. Effects of flavonoid extract Enzogenol ${ }^{\circledR}$ with vitamin $C$ on protein oxidation and DNA damage in older human subjects. Nutr. Res. 23: 1199-1210.

34. Tai A, Sawano T, Yazama F, Ito H. 2011. Evaluation of antioxidant activity of vanillin by using multiple antioxidant assays. Biochim. Biophys. Acta 1810: 170-177.

35. Ko J-W, Lee I-C, Park S-H, Moon C, Kang S-S, Kim S-H, et al. 2014. Protective effects of pine bark extract against cisplatin-induced hepatotoxicity and oxidative stress in rats. Lab. Anim. Res. 30: 174-180.

36. Faria A, Pestana D, Teixeira D, Azevedo J, de Freitas V, Mateus N, et al. 2010. Flavonoid transport across RBE4 cells: a blood-brain barrier model. Cell. Mol. Biol. Lett. 15: 234-241.

37. Verstraeten SV, Keen CL, Schmitz HH, Fraga CG, Oteiza PI. 2003. Flavan-3-ols and procyanidins protect liposomes against lipid oxidation and disruption of the bilayer structure. Free Radic. Biol. Med. 34: 84-92.

38. Ali B, Jamal QMS, Shams S, Al-Wabel NA, Siddiqui MU, Alzohairy MA, et al. 2016. In silico analysis of green tea polyphenols as inhibitors of $\mathrm{AChE}$ and BChE enzymes in Alzheimer's disease treatment. CNS Neurol. Disord. Drug Targets 15: 624-628.

39. Wright CI, Geula C, Mesulam M-M. 1993. Neuroglial cholinesterases in the normal brain and in Alzheimer's disease: relationship to plaques, tangles, and patterns of selective vulnerability. Ann. Neurol. 34: 373-384.

40. Bartus RT, Dean RL, Beer B, Lippa AS. 1982. The cholinergic hypothesis of geriatric memory dysfunction. Science 217: 408-414.

41. Greig NH, Utsuki T, Ingram DK, Wang Y, Pepeu G, Scali C, et al. 2005. Selective butyrylcholinesterase inhibition elevates brain acetylcholine, augments learning and lowers Alzheimer $\beta$-amyloid peptide in rodent. Proc. Natl. Acad. Sci. USA 102: 17213-17218. 